\title{
SIGNIFICAÇÃO PARENTAL ACERCA DO DESVIO FONOLÓGICO
}

\author{
Amanda Schreiner Pereira \\ Márcia Keske-Soares \#
}

\begin{abstract}
RESUMO. Este trabalho objetivou relacionar o desvio fonológico e o discurso parental. Para tanto, baseou-se em uma metodologia qualitativa, a partir da Análise de Conteúdo. Participaram da pesquisa 18 (dezoito) familiar/responsável por crianças diagnosticadas como com Desvio Fonológico e encaminhados ao Centro de Estudo de Linguagem e Fala (CELF) do Serviço de Atendimento Fonoaudiológico (SAF) da Universidade Federal de Santa Maria (UFSM). O instrumento utilizado foi uma Entrevista do Discurso Parental. Os resultados iniciais, obtidos por meio da generalização dos dados das Entrevistas, compararam os participantes quanto à significação parental destinada tanto à criança quanto ao desvio. Observou-se que características comportamentais e temperamentais das crianças estavam ligadas aos discursos parentais, estes não apresentaram relação direta com o Desvio Fonológico.
\end{abstract}

Palavras-chave: Distúrbios articulatórios; patologia da linguagem; discurso parental.

\section{PARENTAL MEANING ABOUT TO SPEECH DISORDER}

\begin{abstract}
The following paper aimed at relating speech disorders and parental speech. The basis was a qualitative methodology through Content Analysis. Eighteen relative/legal responsible-child diagnosed with having Speech Disorder and sent to the Language and Speech Study Center of the Speech Therapy Service at the Federal University of Santa Maria. The used instrument was a Parental Speech Interview, where the parents' wishes concerning the child were checked, the meaning given to the speech disorder and its consequences. The initial results, obtained through the generalization of the Interview data, compare the participants in what concerns parental meaning to the child and the disorder. It was observed that behavioral and temper characteristics of the children being connected to the parental speech, they did not present any direct relation with the Speech Disorder.
\end{abstract}

Key words: Articulation disorders; language pathology; parental discourse.

\section{SIGNIFICACIÓN PARENTAL ACERCA DEL DESVÍO FONOLÓGICO}

RESUMEN. El objetivo del presente trabajo ha sido relacionar el desvío fonológico y el discurso parental. Por lo tanto, se ha basado en una metodología cualitativa, a partir del análisis de contenido. Participaron de la pesquisa 18 (dieciocho) familiares / tutores por niños diagnosticados con Desvío Fonológico y encaminados al Centro de Estudios del Lenguaje y Habla del Servicio de Atención fonoaudiológica (SAF) de la Universidad Federal de Santa Maria (UFSM). El instrumento utilizado fue una entrevista del discurso parental. Los resultados iniciales, obtenidos por medio de la generalización de los datos de las entrevistas, compararon los participantes cuánto a la significación parental destinada tanto al niño cuanto al desvío. Se ha observado que características de comportamiento y temperamento de los niños estaban conectadas al discurso parental, pero estos no presentaron relación directa con el desvío fonológico.

Palabras clave: Disturbios articulatorios; patología del lenguaje; discurso parental ancianos.

A presente pesquisa sustenta a relação entre o Discurso Parental (significações dadas pelos pais ou seus substitutos às crianças) e o Desvio Fonológico.
O desvio Fonológico é uma alteração de fala que persiste além dos quatro anos de idade, tempo em que a maioria das crianças já adquiriu seu sistema

* Mestre em Distúrbios da Comunicação. Psicóloga do Curso de Psicologia da UFSM. Professora do Curso de Psicologia e Coordenadora do Curso de Pós-Graduação em Atendimento Clínico: Abordagem Psicanalítica da ULBRA/Santa Maria.

\# Fonoaudióloga, Doutora em Lingüística Aplicada, Coordenadora do Curso de Pós-Graduação em Distúrbios da Comunicação Humana da Universidade Federal de Santa Maria (UFSM). 
fonológico completo. As crianças com Desvios Fonológicos têm dificuldades em organizar seu sistema de sons, mas não apresentam fatores orgânicos identificáveis que possam estar interferindo em sua fala, desta forma esta pesquisa foi desenvolvida de maneira a identificar fatores psicológicos associado ao desvio.

Tais fatores foram identificados através do lugar simbólico destinado ao Desvio Fonológico no discurso parental, ou seja, da significação dada à criança e ao distúrbio de fala no discurso dos responsáveis pelas mesmas, significação esta calcada no desejo e fantasia parentais.

\section{REVISÃO TEÓRICA}

Segundo Wertzner (2004), o desvio fonológico é uma dificuldade de fala caracterizada pelo uso inadequado de sons, podendo envolver erros em sua produção, percepção ou organização. Ele possui grande ocorrência entre a população infantil e é diagnosticado entre 4 e 8 anos, período que coincide com a entrada na pré-escola.

Grunwell (1990) descreve as características clínicas das crianças com Desvio: fala espontânea quase ininteligível; idade acima de 4 anos de idade; audição normal para a fala; sem anormalidade anatômica e/ou fisiológica no mecanismo de suas falas; sem disfunção neurológica; possuem capacidades intelectuais para o desenvolvimento da linguagem falada; compreendem a linguagem apropriada para a idade; e têm capacidade de linguagem expressiva em termos de vocabulário e extensão do enunciado adequado para a idade.

Desde Ingram (1976) sabe-se que a causa do desvio é desconhecida. Pesquisadoras atuais citam que sua etiologia não está clara (Lamprecht, 1999). Porém, Wertzner (2004) indicou fatores associados: sexo, idade, otite, alterações de vias aérea superiores e histórico familiar. Este último também é encontrado em pesquisas de Papp (2003) e Papp e Wertzner (2006) e Weber et al. (2007).

Mota (2004) fundamenta aspectos do indivíduo que devem ser levados em consideração pela Fonoaudiologia: emocionais, cognitivos, sociais, individuais, motivacionais e familiares devem ser investigados. Alguns destes aspectos são estudados dentro da área da Psicanálise, salienta-se, entre estes, o lugar simbólico no discurso parental.

Para situar o lugar simbólico, é necessário dimensionar a realidade psíquica infantil e a constituição do sujeito. Pergunta-se então: De onde nasce uma criança? Uma criança nasce, primeiro, de um desejo parental.

Pode-se atestar o desejo parental através do discurso: quando eu tiver um filho, irá se chamar "x..........", porque "x.........." significa "y..........". Lacan (1956) diz que o sujeito é servo de um discurso onde seu lugar está inscrito desde o nascimento, ainda que sob a forma de seu próprio nome.

Cada pai ou mãe ou substituto irá preencher estas lacunas conforme desejos particulares. Sabe-se, desde Lacan, que o desejo é constituído a partir de uma falta, de que falta se estaria falando nesta introdução da vida humana?

Fala-se da falta que marca a neurose parental, da incompletude. Diante de seus próprios desejos irrealizados, os pais (ou seus substitutos) depositam na criança a possibilidade de que elas venham a realizarem-nos.

Segundo Kamers e Baratto (2004) a mãe, devido a sua condição de faltante, toma o bebê como objeto privilegiado de seu desejo e supõe no bebê uma demanda endereçada a ela.

Para Laznik-Penot (1997a, 1997b) e Dolto (2002), os que recebem o bebê ao nascer (seus pais, irmãos, avós, outras crianças...) têm um corpo de existência simbólica e vêem o recém-nascido como se também estivesse submetido à ordem simbólica e é nesta aposta que se inaugura o sujeito. Este Olhar primordial é o que permite à mãe escutar nos balbucios do bebê mensagens significantes que ele fará suas mais tarde.

Kamers e Baratto (2004) apontam que este é o primeiro tempo lógico da constituição subjetiva, o tempo da alienação, no qual a criança é capturada pelo Outro. Jerusalinsky (2004a) diz que neste primeiro momento constitutivo, em que ainda não houve barramento do desejo materno, a criança se identifica com a mãe (a mãe é fálica por fazer os filhos sozinha, afinal, as crianças nascem de sua barriga).

Mas, segundo Leite (2004), o sujeito deve recusar o lugar que lhe é designado pelo desejo da mãe, pois equivaler-se a este desejo, seria aniquilar-se.

Assim, é necessário que se instaure a metáfora paterna, ou seja, um barramento do desejo materno. Jerusalinsky (2004a) situa esta metáfora como fundante da fala, ele questiona: por que a criança começa a falar com um ano e meio, dois anos? Porque é o momento em que o Nome-do-Pai começa a fazer sua entrada e a apropriação das palavras oferece uma chance. Ele observa que, quando não há esta entrada, a criança não fala, não se dirige a, não investe na apropriação da língua, apesar de poder repetir fonologicamente pedaços de palavras. 
Conforme Jerusalinsky (1999), as crianças não falam porque amadureceram neurologicamente ou porque aprendem ou imitam, nem para representar imagens e chegar a uma abstração de ações, falam porque este é o único meio em que podem ser. A linguagem se vale da fala. Apesar da maturação biológica dar condições à fala, esta só se desenvolve no sujeito que está no campo da linguagem.

A língua se instala como ato de fala antes de se instalar como sistema, para dar conta de um sentido que falta. É na fala da mãe (mamanhês) que se pode notar as consequiências do ato de fala (Jerusalinsky, 2004a).

Jerusalinsky (1999) afirma que os pais das crianças que não falam não estão dispostos a correr o risco de ouvir uma versão diferente daquela que quiseram dizer e é esta a causa da impossibilidade de tais crianças falarem, uma vez que não são interpelados na posição de quem escuta, pois o que não escuta, não fala.

Conforme Faria e Trigo (2006), não é o sujeito que "percebe" e "interioriza" a linguagem, é ela que o inscreve na ordem do humano. A partir disto, não podem ser usados recursos cognitivos para modificar a linguagem porque é o sujeito que é afetado por ela e não ela pelo sujeito. A partir do momento que o sujeito toma a fala como recurso, percebe que pode usá-la para exprimir suas vontades, expor seus desejos. Deve-se situar então, como o sujeito toma a fala, usa a fala, ou melhor, se situa na fala.

A partir disto, questiona-se que sujeito é este que chega para a Terapia da Linguagem? E que nos casos de Desvios, são trazidos por seus pais/responsáveis? Tkach (1999) coloca que alguns pais que levam suas crianças a tratamento demandam "consertar algo estragado" (sintoma). O risco do terapeuta é de atender a esta demanda.

Jerusalinsky (2004b) diz que quando um traço se transforma em signo por um conceito patológico (nome da doença) adquire o valor de uma imago. Do lado do terapeuta, ele pode tomar o traço, ou seja, aterse mais do lado da imago patognomônica do que do lado da polivalência semântica do significante. Se isto acontece, toda significação fica resumida a este signo (doença) e as justificativas ao traço são designadas a partir dele: é assim porque tem desvio... faz assim porque tem desvio.

Para que isto não ocorra, Faria e Trigo (2006) sugerem que o clínico deve ficar sob o efeito da fala do paciente, do modo como este se posiciona diante da fala do clínico e de sua própria fala, e esta nova posição deve conduzir a avaliação.
Para Vorcaro (2004) as condições corpóreas patológicas de funcionamento da linguagem e da produção da fala são tomadas ora como um sintoma psíquico (cujo valor está no inconsciente), ora como deficiência orgânica (fora da psicanálise).

Ela salienta que as perturbações da fala estão sobredeterminadas pela condição psíquica dos pacientes. Em alguns casos, a insuficiência da sustentação de uma posição subjetiva no laço social recrudesce os sintomas, impedindo que sejam ultrapassados; em outros, o asseguramento da condição subjetiva é suficiente para superar os constrangimentos impostos pelos sintomas (até mesmo os irreversíveis).

Faria e Trigo (2006) apostam que a retirada da linguagem da categoria objeto e a atribuição de uma função estruturante da linguagem na subjetividade pode ser norteador a uma "nova" clínica Fonoaudiológica.

Segundo Borges (2004), apesar das controvérsias entre os que acreditam em causas psi e os que crêem em causas orgânicas, é possível uma clínica que ligue a anatomopatologia dos fenômenos à história da produção singular de representação e linguagem de um sujeito.

Para tanto, diz Trigo (2004) que o fonoaudiólogo deve escutar a fala e o sujeito que fala, procurando empreender como o sujeito é afetado por sua fala e como é afetado pela fala do outro.

Conforme Rodulfo (1990), quando os pais trazem a criança não se deve proceder com um inventário de sintomas (anamnese), pois o sintoma é insuficiente. Em vez de questionar o que tem a criança, questionase: Em que mundo vive o pequeno? Ainda vive no corpo da mãe ou vive em outro território? O que representa esta criança para o desejo dos pais? Para que é/foi desejado? Que lugar ocupa no mito familiar?

Golder (2000) ao tratar do pedido dos pais pela intervenção no sintoma da criança, afirma que, em primeiro lugar, a criança interroga seus pais com seu sintoma. Entender esta interrogação, de onde fala a criança e para quem, é necessário a um procedimento clínico e isto só é possível quando ambos, pais e crianças, são incluídos como interlocutores.

Quanto às repercussões da doença do filho nos pais, Laznik-Penot (1997b) diz que ela é vivida pela mãe como um fracasso tal de sua parte que lhe é muito difícil suportar que um outro possa se ocupar dele em seu lugar. Diante disto, os clínicos devem permitir à mãe uma revalorização narcísica.

Desta forma, é descartado um trabalho apenas curativo e pensado um trabalho integral na terapêutica 
com crianças, levando-se em conta a afetividade e a relação com a família.

\section{METODOLOGIA}

Foi realizada uma pesquisa exploratória de abordagem qualitativa, a qual objetiva lançar hipóteses acerca das questões levantadas. A constituição do corpus da pesquisa e sua análise ocorreu com base na Análise de Conteúdo Qualitativa. A pesquisa foi aprovada pelo Comitê de Ética em Pesquisa (CEP) da USFM em 22/08/2006 e encontra-se sob a identificação do registro: CAAE 0058.0.243.000-06.
Ela faz parte dos estudos desenvolvidos pelo Grupo de Pesquisa "Aquisição, Desenvolvimento e Distúrbios da Linguagem" do CELF, que trabalha com pesquisas envolvendo aquisição, desenvolvimento e distúrbios da linguagem e da fala e que está devidamente registrado no CNPQ.

Participaram da pesquisa 18 responsáveis de crianças que foram diagnosticadas, pelo Centro de Estudos da Linguagem e Fala (CELF) do Serviço de Atendimento Fonoaudiológico (SAF) da UFSM, como com Desvio Fonológico. Como critério de inclusão, os responsáveis deveriam estar convivendo regularmente com as crianças.

O quadro abaixo delimita os sujeitos da pesquisa:

\begin{tabular}{|c|c|c|c|c|}
\hline Sujeito & Vínculo & Sexo da criança & Idade da criança & Tipo de inserção no celf \\
\hline $\mathrm{A}$ & Mãe Biológica & $\mathrm{M}$ & $5: 9$ & Em atendimento \\
\hline $\mathrm{B}$ & Mãe Biológica & $\mathrm{F}$ & $6: 1$ & Em atendimento \\
\hline $\mathrm{C}$ & Mãe Biológica & $\mathrm{M}$ & $6: 5$ & Em atendimento \\
\hline $\mathrm{D}$ & Mãe Biológica & $\mathrm{M}$ & $8: 2$ & Lista de Espera \\
\hline$E$ & Mãe Biológica & $\mathrm{F}$ & $7: 11$ & Lista de Espera \\
\hline $\mathrm{F}$ & Pai Biológico & $\mathrm{M}$ & $6: 1$ & Lista de Espera \\
\hline $\mathrm{G}$ & Mãe Biológica & $\mathrm{F}$ & $5: 10$ & Lista de Espera \\
\hline $\mathrm{H}$ & Pai Biológico & $\mathrm{M}$ & $7: 0$ & Lista de Espera \\
\hline I & Pai Biológico & $\mathrm{F}$ & $7: 9$ & Em atendimento \\
\hline $\mathrm{J}$ & Mãe Biológica & $\mathrm{M}$ & $7: 4$ & Lista de Espera \\
\hline $\mathrm{K}$ & Avó Biológica & $\mathrm{M}$ & $5: 6$ & Em atendimento \\
\hline $\mathrm{L}$ & Mãe Biológica & $\mathrm{F}$ & $6: 0$ & Em atendimento \\
\hline$M$ & Mãe Adotiva & $\mathrm{M}$ & $5: 9$ & Em atendimento \\
\hline $\mathrm{N}$ & Mãe Biológica & $\mathrm{M}$ & $4: 6$ & Lista de Espera \\
\hline $\mathrm{O}$ & Mãe Biológica & $\mathrm{M}$ & $5: 2$ & Lista de Espera \\
\hline $\mathrm{P}$ & Mãe Biológica & $\mathrm{M}$ & $6: 10$ & Lista de Espera \\
\hline Q & Pai Biológico & $\mathrm{M}$ & $11: 1$ & Lista de Espera \\
\hline $\mathrm{R}$ & Mãe Biológica & $\mathrm{M}$ & $4: 1$ & Em atendimento \\
\hline
\end{tabular}

A seleção dos casos dentro do Grupo de Pesquisa do CELF se deu de forma aleatória, a partir dos contatos dispostos pelos responsáveis pelos pacientes.

Realizou-se uma entrevista acerca do Discurso Parental com os responsáveis. As entrevistas foram individuais e gravadas em gravador de voz digital MP3 Player para posterior transcrição e análise e buscou investigar desejos parentais em torno da criança, o lugar dado a ela na família desde sua origem, a concepção de fala dentro desta família, o significado do distúrbio para a mesma, as reações dos responsáveis para com o desvio da criança, entre outros.

Para análise dos dados, primeiramente, foi empreendido um tratamento descritivo, através do registro do discurso dos entrevistados. Em seguida, foi realizada a categorização - classificação de elementos constitutivos de um conjunto por diferenciação e reagrupamento conforme analogia. Após o exame das unidades e categorias, foram feitas reflexões articuladas à fundamentação teórica do estudo.

\section{RESULTADOS E DISCUSSÃO}

A seguir serão apontadas as categorias temáticas obtidas através do processo de categorização das entrevistas com os responsáveis, descritos e comentados trechos ilustrativos das falas dos mesmos e discutidos os resultados obtidos embasados na teoria exposta na Revisão Bibliográfica. 


\section{Categoria 1 - nascimento psicológico}

Inicialmente, um dado: uma das questões a fim de buscar as expectativas parentais - Que pensavam sobre a criança durante este período? - foi respondida por $50 \%$ imediatamente como uma pergunta sobre a expectativa quanto ao sexo da criança. " $O$ objetivo era ter um gurizinho"; "achava que ia ser um menino”. Além do sexo, as perspectivas quanto aos traços: dois sujeitos preocupavam-se com quem a criança seria parecida: pai ou mãe? "Eu imaginava ele parecido comigo fisicamente"

Também houve expectativas quanto à normalidade em $17 \%$ dos casos "achava que iria sair com alguma seqüela no cérebro" (devido às humilhações que sofria no trabalho, pois não foi demitida apenas porque estava grávida). Questiona-se: ao deparar-se com o imaginário "doença" durante a gravidez, a mãe estaria precipitando uma patologia? Visto que uma criança nasce, primeiro, de um desejo parental. A relação inconsciente-sintoma deve ser pensado de forma particularizada, sendo que o estudo não tem o intuito de apontar uma fantasia como causa de desvio, porém, esta fantasia é um aspecto a ser questionado quando individualizado.

Dois sujeitos ainda se disseram realistas: não imaginavam os traços da criança, apesar de conversarem com elas. "Não imaginava ela (os bracinhos, as perninhas), só conversava”; "Eu conversava bastante, até que não tinha imaginação”.

Estes pontos levantados: sexo, traços de identificação e conversas com a criança imaginada salientam a presença da expectativa parental neste ser ainda biológico, como colocado por Laznik-Penot (1997a) e Dolto (2002) quando dizem que os que recebem o bebê ao nascer (seus pais, irmãos, avós, outras crianças...) têm um corpo de existência simbólica e vêem o recém-nascido como sujeito.

Quanto à origem do nome das crianças, em um dos casos observou-se relação com o desvio. No caso A, a mãe diz que a escolha foi feita a partir de um ator de cinema que simbolizava coragem. Esta é a mesma mãe que diz que esperava que o menino nascesse "medroso" por causa de um assalto sofrido durante o período de gestação. O símbolo da coragem se dava através da profissão do ator ao representar personagens em alguns filmes. Investigando a história familiar, registrou-se que um tio materno tem a mesma profissão e que o desejo do menino e de sua mãe é segui-la. Neste tio também foram identificados os mesmos problemas de fala que o menino.

Assim, durante a entrevista, constatou-se uma identificação do menino com uma figura masculina modelo para a mãe. Aqui, pode-se referir a fala de
Lacan (1956) de que o sujeito é um servo do discurso onde está inscrito, mesmo que sob a forma de seu próprio nome.

Assim, a partir do discurso materno, aparece a hipótese de que o sintoma de fala do menino tenha se desenvolvido como forma de identificação deste com o tio.

\section{Categoria 2 - adaptação do novo membro na família}

Observa-se nos registros das entrevistas que grande parte dos responsáveis aponta mudanças na estruturação familiar: separações, adaptações no local onde moram, outros agentes familiares adentrando o espaço familiar (avós). Apontar as mudanças observadas, a reestruturação, é situar a criança como um membro terceiro na família.

Salienta-se que não apenas este membro influenciará na estrutura familiar, mas também será contaminado por ela. Os dramas, conflitos e ambigüidades dos adultos influenciam o desenvolvimento psíquico dos pequenos (Dolto, 2002) e todas as mudanças já citadas denotam que lugar este novo membro vem ocupar.

Um dado interessante: a sustentação da criança no quarto dos pais até uma idade elevada: 3a, 4a, 5a, sendo que as crianças saem dos quartos quando são "substituídas" por outras pessoas: novos esposos, novos irmãos. Em uma das falas a permanência da criança no quarto dos pais se dá pela vinculação da menina com o pai, que troca de lugar na cama com a mulher para ficar mais perto da filha. Não há nenhuma justificativa e falta de espaço na casa para que as crianças durmam com os pais. Será necessário que estas crianças tomem o espaço de um outro? Será que seu nascimento apenas precipita uma crise conjugal já instaurada e a necessidade de colocá-la como uma "desculpa" à falha na relação do casal?

Para descrever a adaptação familiar, os discursos situam as crianças em relação a um outro, relações de alteridade solicitadas pela entrevistadora. Duas mães dizem não suportar a rivalidade das crianças em relação aos pais. Estes têm de ser cuidados como elas, o que levou uma das mães a se separar e acarreta muitas brigas e a falta de "uma vida de casal" no outro caso. Nos dois casos as crianças são meninos.

Quando a relação é com os irmãos, duas mães fazem importantes referências: uma delas diz que, pelas diferenças que constatou em relação ao desenvolvimento do irmão mais velho, acredita que este não é "normal": "Será que ele é doente?”. Outra mãe, que dizia querer uma menina e acaba tendo um menino ("É um menino, mas é normal") refere que este fica "grudado" no irmão durante todo o dia. 
Estas impressões podem ser associadas ao que Groisman e Jerusalinsky (1999) entendem como impossibilidade de pensar na linguagem em si mesma, pensando-a no campo da alienação, da subjetividade em relação a um Outro. Questiona-se: os desvios de fala podem estar relacionados com a falta de espaço destinado às crianças, visto que os pais acabam tomando os lugares de cuidados dispostos pelas mães? Comparando-se às crianças a seus irmãos, há possibilidade de alteridade, visto que as particularidades são aniquiladas?

Alguns discursos também situam as crianças demonstrando uma infantilização através da fala, o que parece estar associada ao desejo paterno e materno de que elas permaneçam bebês. Uma das mães cita que o pai diz constantemente "Este é o nenê do papai" (sendo ele o filho mais novo), "As vezes ele esquece... chama bebê pra cá".

Se, para Souza (2004) a comunicação é entendida como função e potência da linguagem, um desejo de se comunicar com um outro e de por este ser acolhido, pode-se supor que tipo de acolhimento está sendo dado a esta fala.

Em um dos casos a mãe refere que o menino foi criado, praticamente, por uma babá, que também é sua madrinha. Esta, por sua vez, lhe trata ainda como bebê, remetendo ele a suas falas infantis, pois as repete.

Não há outros aspectos, que não a fala, citados como em atraso pelos responsáveis, sendo que não é possível afirmar que estas crianças teriam uma infantilização global do desenvolvimento.

Reportar-se a um conceito de doença, remete à noção de traço patognomônico de Jerusalinsky (2004a). Este fato diz que a doença refere-se a um traço quando não se pode questionar para além dela e pensa-se que, para tudo que a criança produz, há respaldo pela sua condição de doente. Assim, poderse-ia pensar que a infantilização se dá posteriormente à instauração do desvio.

Ao encarar o desvio fonológico como uma patologia, como alguns pais refletem: "Isso não é normal", poder-se-ia pensar que, a partir desta implicação (de doentes), os responsáveis passassem a infantilizá-las. Porém isto não foi atestado em nenhuma das falas das entrevistas. As que referem a infantilização a assumem a partir da concepção, pois os pais as tratam "desde sempre como bebês". Assim, não se pode afirmar que a infantilização, caso ocorra, se dê previamente ou posteriormente à instauração do Desvio Fonológico, ela aparece apenas como característica em algum dos casos e só pode ser tratada em relação a estes quando particularizada.

\section{Categoria 3 - um ser falante: aquisição e complicações}

Inicia-se esta categoria apontando em que momento os responsáveis se deparam com os problemas de fala das crianças. Nota-se que todas os responsáveis que buscaram Atendimento Fonoaudiológico o fizeram após os 4 (quatro) anos de idade, o que corrobora com o estudo de Wertzner (2004), que aponta que o distúrbio é diagnosticado entre 4 e 8 anos, período que coincide com a entrada nas Instituições Educativas. Em 39\% dos sujeitos desta pesquisa, os responsáveis não percebiam, antes da entrada na escola ou creche (em torno dos 3 anos de idade), a dificuldade de fala.

Em $61 \%$ dos casos, os responsáveis afirmaram já ter se deparado com a diferença e a suposição da patologia anteriormente, antes que a criança completasse 3 (três) anos. A justificativa que utilizaram pelo fato de terem percebido precocemente, mas terem levado para atendimento tardiamente está vinculado ao saber do outro, seja este saber técnico (uma opinião médica) ou oriundo de opiniões familiares.

Retomando a percepção dos responsáveis quanto aos desvios fonológicos, muitos apontaram que percebiam o problema "desde o início", quando as crianças não conseguiam falar palavras mais extensas, apenas uma refere que a criança começou a falar tardiamente. A partir disto, pode-se tomar as palavras de Jerusalinsky (2004a) quanto à idade em que a criança começa a falar. Diz ele que a criança inicia-se na fala com 1 ano e meio, 2 anos de idade pois é nesta época que o Nome-do-Pai começa sua entrada no desenvolvimento infantil. Afirma que quando a criança não fala, é sinal de que não investe na apropriação da língua, apesar de poder repetir fonologicamente pedaços de palavras. Desta forma, supõe-se que apenas em um dos casos não há tentativa de apropriação da língua, sendo que esta é fundamental à assunção de Sujeito.

Foi solicitado aos responsáveis que relatassem como iniciaram a percepção quanto à dificuldade de fala de suas crianças. Como resposta, obteve-se a idéia de que a percepção se dá através de palavras-chaves lembradas pelos pais como as de difícil "acesso" à criança. Estas palavras "erradas", todavia, ocasionavam uma dificuldade em dimensionar o que desejavam. Diante disto, as crianças passavam a utilizar outros recursos: gritar, balançar a cabeça, apontar com o dedo.

Podemos identificar estes registros de comunicação como a instauração da língua como ato de fala (descrita por Jerusalinsky, 2004a)? Não, a língua como ato de fala é um processo prévio à 
instalação da língua como sistema e, mesmo que seja através de gestos, estes parecem tentar dar conta de um sentido que falta. Todavia, sem o recurso da fala, ainda não se consegue saber como o sujeito se situa nela.

Além disto, o autor diz que um traço (gesto, toque) só pode se tornar símbolo se adquirir valor representacional, mas isto não garante a entrada na linguagem, pois pode adquirir valor de significante ou de imago. Ou seja, mesmo que apontar para um objeto represente que este objeto é o que a criança deseja, tem-se que observar se este gesto adquire valor significante, o que quer dizer estar do lado da polissemia, não se pode ter certeza quanto ao traço.

Cabe aqui, questionar-se se, diante de todo objeto apontado, de todo grito produzido, haverá a certeza do objeto desejado pela criança ou uma angústia parental acerca deste? Se houve a certeza, a possibilidade de imago se produz, e o espaço polissêmico do sujeito se reduz.

Fala-se aqui de um sujeito que não pode exprimirse, ainda, através da fala, pois é a partir do momento que o sujeito toma a fala como recurso que percebe que pode usá-la para exprimir suas vontades, expor seus desejos. Deve-se situar então, como o sujeito usa a fala, ou melhor, se situa na fala. (Jerusalinsky, 2004a).

\section{Categoria 4 - hipóteses sobre a patologia de fala}

Pode-se dividir em 7 os tipos de hipóteses lançadas pelos 18 participantes:

Uma (6\%) não admitiu a patologia, a mãe pensa que a criança é "normal".

Uma $(6 \%)$ acredita ser um problema comportamental, por causa da linguagem usada pela babá com ele: "porque ao mesmo tempo eu penso que pode ser dessa babá dele, ela tinha muito mimo com ele..., ahhh ela deixava e falava com ele daquele jeito. Ela usava a mesma linguagem com ele...no diminutivo". Salienta-se que esta hipótese também se enquadraria em causa emocional se fosse associada a um lugar infantilizado destinado ao menino. Porém, neste caso a mãe também supõe ser um vício de linguagem pelo uso excessivo e extensivo da chupeta.

Duas (11\%) têm dúvidas entre a causa ser emocional ou genética: "Eu acho assim, ó, como ele é tímido... pode ser também pelo histórico do pai dele”.

Duas $(11 \%)$ pensam haver uma causa física. Em um dos casos, o pai afirma ser em função do parto: “...por causa do parto ...teve que ...tiveram que tirá as pressa”. Em outro, a causa cai sobre a gravidez: "Não sei, ...ela tinha uns oito meses, de gravidez já, eu tava lavando as roupas, daí eu saí e fui entrando pela cozinha iii pingando água, iiii eu peguei, baita de um barrigão iii .. eu cai! Daí eu levei um cagaço, só que eu cai assim, e a primeira coisa que eu fiz foi por a mão"

Duas $(11 \%)$ não sabem e não têm hipóteses sobre a causa do desvio.

Duas (11\%) descartam a causa emocional: "Olha eu não sei te dizer, porque ele não é assustado, é bem tranqüilo..."; "Ele a gravidez já foi bem mais tranqüila, bem mais esperada, bem mais aceita, então se fosse emocional não teria o porquê". Estas mães dizem que, sem a explicação emocional, não podem saber a causa da patologia. Diante destas falas supõese que bastaria querer estar grávida para que a criança fosse desejada, já se observou que o desejo, por ser inconsciente, é único, e que cada ser gerado será constituído dentro de uma história familiar e os desejos inconscientes em relação a esta criança poderão ser os mais diversos. Ou seja, o desejo não está situado em querer ter um bebê, mas em que função este vem ocupar (Rodulfo, 1990).

Quatro (22\%) acreditam que a causa seja genética, pois associam o desvio da criança às características de fala de outros familiares, acreditando que estes tiveram o mesmo distúrbio: "Eu não sei se é uma coisa familiar, eu já tenho dificuldade numa coisa, pensei que fosse de mim”; "Eu não sei se foi por causa, talvez, da minha parte, da parte do pai dele. Ele também falava errado... isso pode ser genético...".

Quatro (22\%) crêem tratar-se de causas emocionais: “...porque ela nasceu prematura, teve que ficar em hospital ...ela teve que tomar muito remédio, ...isso deve ter influenciado nela, dentro dela, assim ...emocional"; "Foi criado com tia, avó e muito mimo, se dão muito mimo ou o quê? que a gente não... e também ele é bem rebelde assim, pra gente corrigi ele em casa. Até pra estudo, assim colégio" (justifica que a ausência dela ajudou a gerar o problema).

Neste caso, e no outro, situado com questões comportamentais, observa-se o registro do "mimo" como causa ao desvio. A idéia do "mimo" remete a um espaço sempre ocupado, a uma criança sempre gratificada, uma criança que, não frustrada, é lesada em sua necessidade de ausência.

Observa-se, assim, que as duas hipóteses de maior relevância foram a de causa genética e a de causa emocional. Isto corrobora com o que Vorcaro (2004) afirma sobre como as produções de fala ora são tomadas como um sintoma psíquico (cujo valor está no inconsciente), ora como deficiência orgânica (fora da psicanálise), ambas excluindo a implantação do simbólico no orgânico, que subverte-se a uma 
condição enunciativa que distingue uma posição subjetiva singular.

Dentre os sujeitos que acreditam que a causa seja emocional, uma cita não saber o porquê da fala ter sido afetada: "A gente não sabe por que foi na fala, porque falar é o que ela mais gosta, neh, não pára um minuto de falar! A gente não sabe assim... E especificamente atacou a fala dela, neh?" Destaca-se que, nesta família, há, desde o nascimento da menina, um segredo quanto à identidade do pai (nunca foi-lhe revelado quem era seu verdadeiro pai biológico).

Neste caso pode haver relação do sintoma da fala com o segredo familiar. Assim, ter-se-ia clara a função do sintoma: Jerusalinsky (2004a) afirma que os pais das crianças que não falam não estão dispostos a correr o risco de ouvir uma versão diferente daquela que quiseram dizer e é esta a causa da impossibilidade de tais crianças falarem. Todavia, isto está restrito a apenas este caso.

\section{CONSIDERAÇÕES FINAIS}

Uma característica já apontada em pesquisas anteriores (Wertzner, 2004; Papp, 2003; Papp \& Wertzner 2006; Weber et al, 2007), o histórico familial e sua suposição de causalidade genética, pode ser observada nesta: $50 \%$ dos responsáveis citam que há casos semelhantes na família.

A partir de todos os dados levantados e discussões realizadas até então, pôde-se atestar a existência do nascimento psicológico, a influência dos lugares dispostos nos discursos parentais nas características da criança, os lugares destinados aos diferentes personagens na família e a necessidade da condição de faltante para que o filho tenha um espaço simbólico.

Afirma-se que há uma significação parental ao desvio e uma hipótese para o seu surgimento. Acredita-se que estas devem ser trazidas ao conhecimento do clínico responsável pelo tratamento da criança para que ele os utilize ou como material terapêutico, ou para que desmistifiquem os pais em relação aos mesmos. Ainda, lança algumas hipóteses pertinentes à patologia: em alguns casos seria ela uma via de identificação? Em outros, um atestado de infantilização da criança?

Faria e Trigo (2006) afirmam que a clínica Fonoaudiológica permeada pela Psicanálise implica na busca dos porquês das falas sintomáticas. No entanto, parece que estes porquês não podem ser buscados em generalizações e devem seguir a natureza particular dos sintomas, apoiando-se, para tais interpretações, no viés Psicanalítico. Ainda assim, pode-se questionar em que nível de apropriação em relação a suas próprias falas estão as crianças com desvio fonológico, o que pode nortear futuras pesquisas.

\section{REFERÊNCIAS}

Dolto, F. (2002) Tudo é Linguagem. $2^{\mathrm{a}}$ ed. São Paulo: Martins Fontes.

Faria, V. O. \& Trigo, M. F. (2006) Contribuições da psicanálise na abordagem das falas sintomáticas de crianças. COLÓQUIO DO LEPSI IP/FE-USP, 5. Recuperado em 16 de setembro de 2007 em http://www.proceedings.scielo.br/scielo.php?script=sci_artt ext\&pid=MSC0000000032006000100060\&lng=en\&nrm=a bn

Golder, E. (2000) Clínica da Primeira Entrevista. RJ: Jorge Zahar Editor, 2000.

Groisman, M. L. \& Jerusalinsky, A. (1999) Terapêutica da Linguagem: Entre a voz e o significante. Em Jerusalizky, A. et al. Psicanálise e Desenvolvimento Infantil ( $\mathrm{pp}$ 236-251). $2^{\mathrm{a}}$ ed revista e ampliada. POA: Artes e Ofícios.

Grunwell, P. (1990) Os Desvios Fonológicos Evolutivos numa Perspectiva Lingüística. Em Yavas, M. Desvios Fonológicos em Crianças. Teoria, Pesquisa e Tratamento (pp 53-77). Porto Alegre: Mercado Aberto.

Ingram, D. (1976) Phonological disability in children. London: Whurr Publishers Limited.

Jerusalinsky, A. (1999) Falar uma Criança. Jerusalizky, A. et al. Psicanálise e Desenvolvimento Infantil (pp 50-62). $2^{\mathrm{a}}$ ed revista e ampliada. POA: Artes e Ofícios.

Jerusalinsky, A. (2004a) A metáfora paterna e sua relação com a alíngua. Em Vorcaro (Org). Quem fala na língua? Sobre as psicopatologias da fala (pp 73-92). Salvador: Ágalma.

Jerusalinsky, A. (2004b) A Cura e o Discurso. Em Vorcaro (Org). Quem fala na língua? Sobre as psicopatologias da fala (pp 29-53). Salvador: Ágalma.

Kamers, M. \& Baratto, G. (2004) O discurso parental e sua relação com a inscrição da criança no universo simbólico dos pais. Psicologia: Ciência e Profissão, São Paulo, 24(3), 40-47.

Lacan, J. (1956) O Seminário - Livro 4: As relações de objeto. Rio de Janeiro: Jorge Zahar Ed, 1995.

Lamprecht, R. R. (1999) Aquisição da Linguagem. Questões e Análises. POA: EdiPUCRS.

Laznik-Penot, M. C. (1997a) Poderíamos pensar numa prevenção da Síndrome Autística? (pp 35-51). Em Wanderley. Palavras em torno do berço. Salvador, BA: Agálma.

Laznik-Penot, M. C. (1997b) Rumo à Palavra. Três Crianças Autistas em Psicanálise. São Paulo: Escuta.

Leite, N. V. A. (2004) Corpolinguagem. Em Vorcaro (Org). Quem fala na língua? Sobre as psicopatologias da fala (pp 180-188). Salvador: Ágalma. 
Mota, H. B. (2004) Fonologia: Intervenção. Em Ferreira, L. P., Befi-Lopes, D. M. \& Limongi, S. C. O. Tratado de Fonoaudiologia. (pp 788-814) São Paulo: Rocca.

Papp, A. C. C. (2003) Um estudo sobre a relação do aspecto familial e o distúrbio fonológico. São Paulo, SP, 90p. Dissertação de Mestrado em Semiótica e Lingüística Faculdade de Filosofia, Letras e Ciências Humanas da Universidade de São Paulo, SP.

Papp, A. C. C. S. \& Wertzner, H. F. (2006) O aspecto familial e o transtorno fonológico. Pró-Fono Revista de Atualização Científica, Barueri (São Paulo), 18(2), 151-160.

Rodulfo, R. (1990). O Brincar e o Significante. POA: Artmed.

Souza, L. A. de P. (2004) Linguagem e Corpo. Em Ferreira, L. P., Befi-Lopes, D. M. \& Limongi, S. C. O. Tratado de Fonoaudiologia (pp 892-898). São Paulo: Rocca.

Tkach, C. E. (1999) Reflexões sobre nossa prática terapêutica. Em Jerusalinsky, A. et al. Psicanálise e Desenvolvimento Infantil (pp 303-306). $2^{\mathrm{a}}$ ed. Porto Alegre: Artes e Ofícios.
Trigo, M. F. (2004) Sobre os distúrbios articulatórios: a heterogeneidade em questão na clínica da linguagem. Estudos Lingüísticos, XXXIII, 1250-1255.

Vorcaro, Â. (2004) Das manifestações psicopatológicas da fala. Em Vorcaro (Org). Quem fala na língua? Sobre as psicopatologias da fala (pp 13-26). Salvador: Ágalma.

Weber, D. E. et al. (2007) Desenvolvimento do Sistema Fonológico de Gêmeos Monozigóticos com Desvio Fonológico: Correlação a Fatores Genéticos e Ambientais. Revista CEFAC. 9(1), 32-9.

Wertzner, A. F. (2004) Fonologia: Desenvolvimento e Alterações. Em Ferreira, L. P., Befi-Lopes, D. M. \& Limongi, S. C. O. (Org.), Tratado de Fonoaudiologia (pp 772-786). São Paulo: Rocca.

Recebido em 20/12/2007 Aceito em 08/05/2008

Endereço para correspondência : Amanda Schreiner Pereira. Rua Prof. João Belém, 17, AP. 402, Bairro Centro, CEP 97015-540, Santa Maria, RS, Brasil. E-mail: psico_amanda@hotmail.com 
